\title{
Frequency of Procedural Errors during Root Canal Treatment Performed by House Officers in Private Teaching Dental Hospital
}

Syed Abrar Ali, Mehmood Hussain, Muhammad Shahzad, Hina Nafees

\begin{abstract}
OBJECTIVE: To determine the procedural errors produced during the conventional root canal treatment and to find out the association of errors with particular teeth.

METHODOLOGY: This descriptive observational type study was conducted in Private Teaching Dental Hospital. A total 200 root canal treated teeth were assessed through peri-apical radiographs using non-probability convenient sampling technique. The data was collected from patient record files retrospectively performed by house officers in the duration of 1 year in department of Operative Dentistry. Data analysis was done by using SPSS version 22. Frequency and percentage statistics were used.

RESULTS: Out of sample size of 200 patients, $110(55 \%)$ were females and $90(45 \%)$ were males with age range from 10 to 50 years. The most frequently treated tooth was the mandibular right first molar $(29.5 \%)$ followed by permanent maxillary right first molar(26\%). The most frequent tooth to possess an error was the mandibular right first molar (59\%), followed by maxillary right first molar $(52 \%)$. Instrument separation was the most common procedural error 148 (74\%), followed by ledge $25(12.5 \%)$.

CONCLUSION: The results concluded that instrument separation was the most frequent procedural error and the most frequent tooth to possess an error was the mandibular right first molar.
\end{abstract}

KEYWORDS: Procedural Errors, Root canal treatment

This article may be cited as: Ali SA, Hussain M, Shahzad M, Nafees $\mathrm{H}$. Frequency of Procedural Errors during Root Canal Treatment Performed by House Officers in Private Teaching Dental Hospital. J Liaquat Uni Med Health Sci. 2019;18(01):55-9.

doi: 10.22442/jlumhs.191810601

\section{INTRODUCTION}

The goal of the root canal treatment is to save the tooth $^{1}$. The complex morphology of the root canal system varies among individuals and populations ${ }^{2,3}$. A clear understanding of the variation of root canal anatomy is an important criterion for a successful endodontic procedure involving cleaning and shaping of root canals ${ }^{4-6}$. Endodontic errors such as instrument separation, ledge, strip perforation, apical perforation, zipping, apical transportation, overfilled, under filled teeth can occur during diagnosis, access preparation, instrumentation, obturation, and postspace preparation, make treatment completion difficult and jeopardize treatment outcome ${ }^{7}$.

A study by Siddique FA $2016^{8}$ on the frequency of procedural errors during RCT performed by interns was conducted in hospital setting in Pakistan showed apical transportation as the most common procedural error $(12 \%)$ followed by ledge $(10 \%)$ and instrument separation was found to be (4\%). The high incidence of apical transportation in their study reflects the skills and technique followed by their interns, the other factors contributing to this high frequency of errors could be aggressive filing, failure to pre-curve the file in case of curved root canals using fatigued files, use of stainless steel files and also the use of step-back technique ${ }^{8}$.

A study by Yousuf W $2015^{7}$ on endodontic procedural errors: frequency, type of error, and the most frequently treated tooth by postgraduate trainees was conducted in hospital setting in Pakistan showed $(22.7 \%)$ teeth were GP extrusion, $(8.9 \%)$ were under-filled, $(0.9 \%)$ had instrument separation and $(0.4 \%)$ had apical transportation. The most frequently treated tooth was right permanent mandibular first molar (11.3\%). The reason for GP extrusion was due to inadequate length determination or over instrumentation.

A study by Alsulaimani R $2016^{9}$ on the correlation between endodontic mishaps and single-visit treatment amongst dental students was conducted in King Saud University Saudia Arabia showed the apical transportation as the most prevalent procedural error (39\%) followed by ledge (34.5\%).

A number of factors can affect the perception, clinical efficiency and performance of Interns ${ }^{10,11}$. The procedural errors can be avoided by a dentist by relying on his knowledge, intuition, and patience 
during the course of the treatment. In our Institution the students are taught the crown down technique with $\mathrm{NiTi}$ files. Several challenges are present at the house job [internship] level resulting in procedural accidents. Hence, further studies should be carried in future about etiology and management of procedural errors to improve the understanding of young clinicians that can help to obtain better clinical outcome.

\section{METHODOLOGY}

The study was Descriptive Observational type in which data was collected retrospectively at single point in time from record files. Sample size was calculated by using www.statistics.co.uk. At 95\% confidence level, $80 \%$ power of study the sample size was calculated to be $n=106$ and increase to 200 . The teeth were assessed through peri apical radiographs and reported in department of Operative Dentistry at Private Teaching Dental Hospital, Karachi from $1^{\text {st }}$ January 2017 to $1^{\text {st }}$ January 2018.

Inclusion criteria includes Root canal treated teeth, Maxillary and Mandibular molars with history of irreversible pulpitis or necrosed pulp. Patients aged between 10 years -50 years, Teeth prepared with conventional $\mathrm{Ni} \mathrm{Ti}$ files, Root canal treatment performed by house officers, Preoperative and Postoperative periapical radiographs present in the record files, All root canal treatments was done under indirect supervision, however, if there is any procedural error occurred, it is obligatory in hospital policy for re-treating it and mentioned in the files.

Exclusion criteria was teeth with open apices, Teeth with blocked or calcified canals, External / internal root resorption, Periapical pathology (such as cysts and tumors), Advanced periodontal conditions/perio-endo lesions, All teeth were prepared using the crown down technique. Irrigation was done using $2.5 \% \mathrm{NaOCl}$ and was obturated using lateral condensation technique. Crown down technique was performed using hand protaper files and were used in the sequence ofSX,S1, S2, F1 and F2. Working length was determined by using radiographs and it was acceptable if it was within $0-2$ mmof the radiographic apex by a periapical radiograph using a paralleling technique. Data was analyzed using SPSS version 22 using simple descriptive analysis.

Evaluation criteria were: Ledge was labelled on radiograph when file was deviated from the canal curvature and was short from the working length ${ }^{12}$, Apical transportation was diagnosed radiographically when the filling material was located outside curve of the canal at the apical third ${ }^{12}$, Apical perforation was diagnosed radiographically when the filling material was extruding through the apical foramen ${ }^{12}$, Strip perforation was diagnosed radiographically when extrusion of filling material was detected in the lateral wall of the root canal ${ }^{12}$, Instrument Separation was diagnosed radiographically when a fractured instrument was detected inside a root canal or when its tip extended into the periapical area ${ }^{12}$, Zipping was diagnosed radiographically when the apical termination of the filled canal appeared as an elliptical shape transported to the outer wall ${ }^{12}$.

Before conducting this research, an approval has been taken from the "Ethical Committee of the Research Centre at Private Teaching Dental Hospital" and the Patient Record department.

\section{RESULTS}

Total $n=200$ root canal treated tooth were assessed out of which $110(55 \%)$ belonged to females and 90 $(45 \%)$ belonged to males. The mean age of the patients was 30.7[S.D \pm 7.03 ] years. The most frequently treated tooth was the mandibular right first molar $(29.5 \%)$ followed by permanent maxillary right first molar $(26 \%)$, maxillary left first molar $(13 \%)$, mandibular left first molar (12\%), mandibular right second molar $(9.5 \%)$, maxillary right second molar (7.5\%), mandibular left second molar $(5 \%)$ and maxillary left second molar $(2 \%)$. The most frequent tooth to possess an error was the mandibular right first molar $(59 \%)$, followed by maxillary right first molar (52\%). (See Graph I). The most frequent separated file was SX-S280(53.6\%) followed by F1-F3 69 $(43.0 \%)$.(See Table I). Instrument separation was the most common procedural error $148(74 \%)$, followed by ledge $25(12.5 \%)$. (See Table II). Most procedural errors were performed by female house officers. (See Table III)

GRAPH I: DISTRIBUTION OF TEETH POSSESS AN ERROR

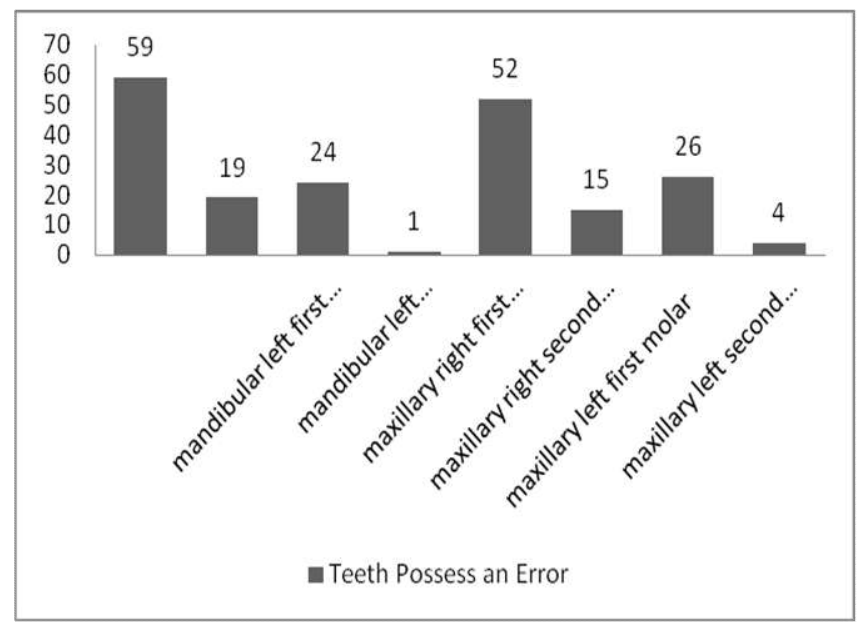


Syed Abrar Ali, Mehmood Hussain, Muhammad Shahzad, Hina Nafees

TABLE I: SHOWING DISTRIBUTION OF FILE NO. DURING INSTRUMENT SEPARATION ERROR

\begin{tabular}{|c|c|c|}
\hline File Number & $\mathbf{n}$ & $\%$ \\
\hline SX-S2 & 80 & 53.6 \\
\hline F1-F3 & 69 & 46.0 \\
\hline Total & 149 & 100.0 \\
\hline
\end{tabular}

TABLE II:

SHOWING FREQUENT PROCEDURAL ERRORS

\begin{tabular}{|l|c|c|}
\hline \multicolumn{1}{|c|}{ Procedural Errors } & $\mathbf{n}$ & $\mathbf{\%}$ \\
\hline File separation & 148 & 74.0 \\
\hline Ledge & 25 & 12.5 \\
\hline Apical perforation & 11 & 5.5 \\
\hline Strip perforation & 2 & 1.0 \\
\hline Zipping & 6 & 3.0 \\
\hline Sodium hypochlorite accident & 3 & 1.5 \\
\hline Apical transportation & 5 & 2.5 \\
\hline Total & 200 & 100.0 \\
\hline n= sample size & & \\
\hline
\end{tabular}

TABLE III: SHOWING DISTRIBUTION OF VARIOUS ERRORS MADE BY THE MALE AND FEMALE HOUSE OFFICERS

\begin{tabular}{|l|c|c|c|}
\hline \multirow{2}{*}{ Procedural Error } & \multicolumn{2}{|c|}{ HO Gender } & \multirow{2}{*}{ Total } \\
\cline { 2 - 3 } & Male & Female & \\
\hline File separation & 48 & 100 & 148 \\
\hline Ledge & 11 & 14 & 25 \\
\hline Apical perforation & 5 & 6 & 11 \\
\hline Strip perforation & 1 & 1 & 2 \\
\hline Zipping & 1 & 5 & 6 \\
\hline $\begin{array}{l}\text { Sodium hypochlorite } \\
\text { accident }\end{array}$ & 1 & 2 & 3 \\
\hline Apical transportation & 0 & 5 & 5 \\
\hline Total & 67 & 133 & 200 \\
\hline
\end{tabular}

\section{DISCUSSION}

Endodontic treatment can be considered a stressful procedure. It usually requires competent technical skills and experience, as well as an understanding of pulp anatomy and its variations. Knowledge of root canal morphology and pulp chamber will allow the student to avoid any mishaps. Perforation of pulp chamber can occur while searching the canal orifices, drilling a tooth with a completely calcified chamber, orienting the bur to the wrong direction, or looking in wrong direction for the other canal. Endodontic treatment is frequently performed on first molar teeth $^{13}$. In present study it is found that mandibular right first molar is most frequently treated tooth and $59 \%$ of procedural errors is associated with it. It is due to narrow and curved canals of these teeth which can negatively effect during root canal instrumentation and make RCT more challenging.

In the present study, Instrument separation was found to be the most common procedural error $(74 \%)$ followed by ledge(12.5\%). A study by Siddique FA $2016^{8}$ on the frequency of procedural errors during RCT performed by interns showed Apical transportation as the most common prevalent error $(12 \%)$ followed by ledge $(10 \%)$ and instrument separation was found to be $(4 \%)$ which differs from the results in the present study. Csinszka $\mathrm{K}-\mathrm{IA}^{14}$ showed $51.5 \%$ ledge formation by dental students using step-back technique. McKendry DJ $1988^{15}$ showed $37 \%$ ledge formation with K-Flex files. Shenoy A $2014{ }^{16}$ reported $30 \%$ ledge formation using K-Files. Another study by Balto H $2010^{17}$ showed $14 \%$ ledges, $7 \%$ apical transportation, and $7 \%$ apical perforation which differs from the results in the present study.

The high incidence of Instrument separation in our study reflects the skills and technique followed by our house officers, the other factors contributing to this high frequency of errors could be aggressive filing, failure to pre-curve the file in case of curved root canals using fatigued files and setting larger MAF since the files become stiffer as the diameter of the files increases, using inappropriate sequence of files and use of poor quality of stainless steel files. Shenoy A $2014^{16}$ and Rambabu T $2014^{18}$ proposed that the blunt tip design of the modern hand and rotary instruments make coronal flaring easier and safer. Use of rotary $\mathrm{NiTi}$ instruments, minimizes the risk of procedural accidents during root canal treatment. Another study reported $0 \%$ ledge formation using ProTaper rotary system and $5.8 \%$ using hand files step back technique, but the initial startup cost for rotary instrumentation can be expensive, and the overhead cost is also high in maintaining a supply of files ${ }^{17}$.

Poor community awareness may also play a role which results in patients reporting to the dentist only 
when they experience severe pain, leading to progression of the disease process to the extent that endodontic treatment is required. In our country patient's low income and lack of education (particularly awareness as regards oral health) act as a barrier to receiving even routine dental checkups. Thus, early detection of any disease process is often not possible and delays preventive treatment, leading to more cases of endodontic treatment. Furthermore, less expertise, lack of specialist practice, and an abundance of roadside quacks also contributed to patient's poor previous dental experience, making them reluctant to seek early dental treatment.

\section{CONCLUSION}

We concluded that the instrument separation was the frequent procedural error and the most frequent tooth to possess an error was the mandibular right first molar. This would help practitioners to determine which steps of the endodontic procedure requires greater diligence, in order to substantially improve the quality of their work and ensure better long term viability of the treatment.

\section{STRENGTH}

We included work that had been done by two different batches of house officers to avoid selection bias.

\section{LIMITATIONS}

In our study results showed that female house officers performed more procedural errors, the reason being that female enrollment already high. The other limitation is that one radiographic technique was used to assess the procedural error.

Conflict of Interest: No.

Funding: No

\section{REFERENCES}

1. Estrela C, Pécora JD, Estrela CRA, Guedes OA, Silva BSF, Soares CJ, et al. Common Operative Procedural Errors and Clinical Factors Associated with Root Canal Treatment. Braz Dent J. 2017; 28 (2):179-190. doi: 10.1590/0103-6440201702451.

2. Alrahabi M, Zafar MS. Evaluation of root canal morphology of maxillary molars using cone beam computed tomography. Pak J Med Sci. 2015; 31 (2):426-30. doi: 10.1266 9/pjms.312.67 53

3. Zafar MS, Alrahabi M. Cone beam computed tomography for exploring morphology of mandibular first molar. BJMMR. 2015; 6(5):514-
21. doi:10.9734/BJMMR/2015/15189

4. Chaurasiya S, Yadav G, Tripathi AM, Dhinsa K. Endodontic Failure and its Management. Int J Oral Health Med Res. 2016; 2(5):144-48.

5. Hülsmann $M$, Peters $O A$, Dummer PM. Mechanical preparation of root canals: shaping goals, techniques and means. Endodontic topics. 2005;10(1):30-76.

6. Zafar MS. Assessment of Antimicrobial efficacy of MTAD, Sodium Hypochlorite, EDTA and Chlorhexidine for Endodontic Applications: An In Vitro study. Middle-East J Sci Res. 2014; 21(2): 353-7. doi: 10.5829/idosi.mejsr.2014.21.02.524

7. Yousuf $W$, Khan M, Mehdi H. Endodontic procedural errors: Frequency, Type of error, and the most Frequently Treated Tooth. Int J Dent. 2015; 2015: 1-7. doi:10.1155/2015/673914

8. Siddique FA, Sheikh AB, Raheed S, Najeeb S, Zafar SM. Frequency of Procedural Errors during Root Canal Treatment Performed by Interns. BBJ. 2016; 12(1): 1-8. doi: 10.9734/BBJ /2016/23768

9. Alsulaimani R, Almanei K, Ababtain R, Binrabba $\mathrm{R}$, Ashri N. The Correlation between Endodontic Mishaps and Single-Visit Treatment in King Saud University. Int J Dent Oral Health. 2016; 2(9): 1-5.

10. Alrahabi M, Zafar MS, Ahmed N. Effects of handpiece speed on the performance of undergraduate dental students in preclinical training. J Taibah Uni Med Sci. 2015; 10(1):50-55.

11. Karimi Z, Chala S, Sakout M, Abdallaoui F. Strategies for intracanal separated instrument removal: a review. Dental Update. 2017; 44 (7):636-46. doi: 10.12968/denu.2017.44.7.636

12. AbuMostafa A, Ahmad IA, Alenezy G, AlZoman A. Quality of root canal filling performed by undergraduate students in a Saudi Dental College. J Dent Oral Hygiene. 2015; 7(5):64-70.

13. Alhekeir DF, Al-Sarhan RA, Mokhlis H, Al-Nazhan $\mathrm{S}$. Endodontic mishaps among undergraduate dental students attending King Saud University and Riyadh Colleges of Dentistry and Pharmacy. Saudi Endodontic J. 2013; 3(1):25-30.

14. Csinszka K-IA-, Maria MA, Monica M, Mihai $P$, Angela B. Identification of the Procedural Accidents During Root Canal Preparation Using Digital Intraoral Radiography and Cone Beam Computed Tomography. Acta Medica Marisiensis. 2016; 62(3):326-329. doi:10.1515/amma-20160028. 
15. McKendry DJ, Krell KV, McKendry LL. Clinical incidence of canal ledging with a new endodontic file (Abstract). J Endod. 1988; 14:194-5.

16. Shenoy A, Mandava P, Bolla N, Vemuri S. A novel technique for removal of broken instrument from root canal in mandibular second molar. Indian $\mathrm{J}$ Dent Res. 2014; 25(1):107-10. doi: 10.4103/09709290.131157.
17. Balto $\mathrm{H}, \mathrm{Al}$ Khalifah $\mathrm{SH}, \mathrm{Al}$ Mugairin $\mathrm{S}, \mathrm{Al}$ Deeb $\mathrm{M}$, Al-Madi E. Technical quality of root fillings performed by undergraduate students in Saudi Arabia. Int Endod J. 2010; 43(4):292-300. doi: 10.1111/j.1365-2591.2009.01679.x.

18. Rambabu T. Management of fractured endodontic instruments in root canal: A review. J Sci Dent. 2014; 4(2):40-48.

AUTHOR AFFILIATION:

Dr. Syed Abrar Ali (Corresponding Author) Associate Professor, Department of Operative Hamdard University Dental Hospital/

Hamdard College of Medicine and Dentistry Hamdard University, Karachi, Sindh-Pakistan.

Email: dentist4@hotmail.com

\section{Dr. Mehmood Hussain}

Associate Professor, Department of Prosthodontic Hamdard University Dental Hospital/

Hamdard College of Medicine and Dentistry

Hamdard University, Karachi, Sindh-Pakistan.

\section{Dr. Muhammad Shahzad}

Associate Professor

Oral and Maxillofacial Surgery

LUMHS, Jamshoro, Sindh-Pakistan.

\section{Dr. Hina Nafees}

FCPS II Resident Operative Department

Hamdard University Dental Hospital/

Hamdard College of Medicine and Dentistry

Hamdard University, Karachi, Sindh-Pakistan. 